\title{
Influence of building shapes on thermal and energy performances in glass façade high-rise buildings: A review
}

\author{
Nurul Hidayah Roslan ${ }^{1,2, *}$, and Mohd Rodzi Ismail $^{2}$ \\ ${ }^{1}$ Faculty of Engineering Technology, Universiti Tun Hussien Onn Malaysia, 84600, Johor, Malaysia \\ ${ }^{2}$ School of Housing, Building \& Planning, Universiti Sains Malaysia, 11800 USM, Penang, Malaysia
}

\begin{abstract}
A high demand of high-rise buildings in the construction industry is due to rapid urbanisation to cater for increasing population in the cities. Application of glass as a façade material becomes a trend in high-rise buildings construction due to its lightness that reduces the buildings' dead load and at the same time increases the number of floors. However, this has become an issue as it contributes to the increase of urban heat island phenomena, global warming and causes thermal discomfort in tropical climate if it is not designed properly. This paper reviews the effects of building shape with different geometric factors (i.e. building orientation and window-to-wall ratio) on thermal comfort and energy performances in glass façade high-rise buildings, as well as discusses the solution or optimum range of the factors. The review provides an information about the most influential shape factors on buildings that a designer considers at the early design stage to optimise thermal comfort and reduce the building energy consumption.
\end{abstract}

\section{Introduction}

Globally, population in rural areas are lesser than in the urban areas. According to World Urbanization Prospects: The 2014 Revision [1], 70\% of the world's population lived in rural areas, while only $30 \%$ lived in urban areas in the year 1950 . However, the latter kept increasing up to $54 \%$ in the year 2014 and it is projected to reach more than $70 \%$ in the year 2050 , due to economic growth and job opportunities in urban cities. Increasing population and high living standards have caused the increase in energy demand in recent years. In order to accommodate a large number of population, a drastic amount of high-rise office or residential buildings have been constructed to provide necessary workplaces and living environments, due to lack of land area.

Nowadays, full glass façade high-rise buildings have become a trend all around the world including in the tropical climate countries. The use of glass is preferred due to its lightness, fast to construct, and its flexibility in producing a unique and futuristic facade of a building. Furthermore, modern glass has its own properties in reducing the impact of thermal, as well as increasing the visual comfort to building occupants.

\footnotetext{
* Corresponding author: nurulhidayahroslan88@yahoo.com
} 
The most important factor that needs to be considered when applying a glass façade is its heat or solar transmission properties, which control heat transmission into the space or reflect heat at the façade's surface. The former affects the thermal condition indoors while the former could contribute to urban heat island phenomena and global warming oudoors. Application of glass with good material properties will help in reducing these effects.

Thermal comfort of the building occupants is one of the main factors in designing a sustainable building. The most important factor in indoor thermal comfort is the temperature of the room as a human is very sensitive to temperature change. A better indoor thermal environment can be achieved by using the air-conditioning system to cool the space especially in tropical climate. Almost all office buildings in the tropical climate region are air-conditioned to enhance comfort to the occupants.

When applying the air-conditioning system, tightness of the building is very important to ensure that there is no outside air infiltration to the space. Air circulation inside the airconditioned space depends on air velocity provided by the air-conditioning system. It is the opposite when natural ventilation is used where air movement is influenced by the velocity of outside air. Hence, a proper design criteria needs to be adopted, especially the building geometry factor, to ensure the effectiveness of air-conditioning system and reduce its effects on energy consumption.

Numerous studies have been conducted on building energy consumption as part of sustainability initiatives. Nevertherless, there have been limited studies on the optimum building shape and geometric factors thus its relations to building energy consumption. Building geometry such as orientation and window-to-wall ratio (WWR) play important roles in building design.

Santamouris [2] stated that the energy consumed in buildings is almost $40 \%$ of the world energy consumption. From that figure, $50 \%$ of it comes from the energy consumed by the air-conditioning system in a standard building $[3,4]$. This has caused intense researches in reducing energy demand and lead to sustainable growth of the building. A lot of indicators have been adopted to construct a sustainable building. The important criteria in designing a sustainable building is its energy consumption. Rubio-Bellido et al. [5] stated that the current focus in building science research and development is to investigate the future energy consumption, which later forecasts its impact on future global climate.

Fig. 1 summarises the causes and effects of glass façade high-rise buildings application in tropical climate. Generally, a proper building design is very important in providing human comfort and reducing the energy consumption, thus its effects to the environment. This paper focuses on the effects of building shapes with different geometric factors (i.e. building orientation and WWR) on thermal comfort and energy performances in glass façade high-rise buildings.

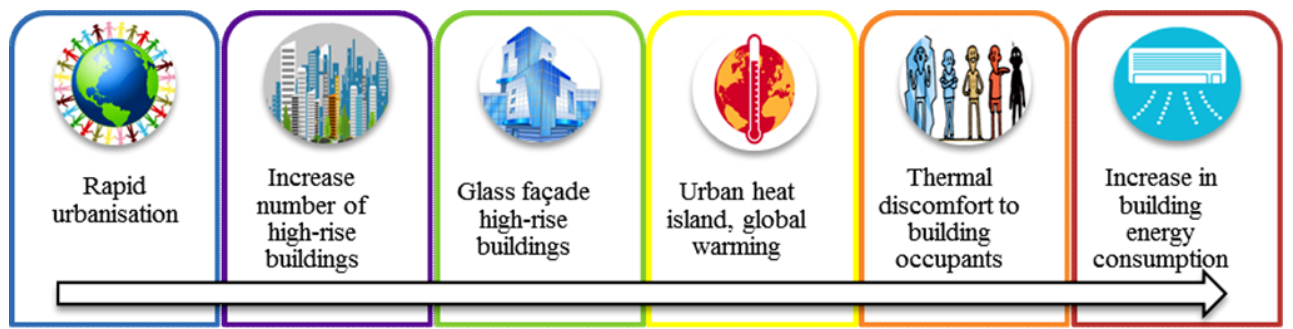

Fig. 1. Causes and effects of glass façade high-rise buildings application in tropical climate. 


\section{General Concept}

Fig. 2 shows the conceptual framework of this review, which includes previous studies for the past ten years. The first part of the review discusses the shape factor and its effects, followed by the discussion on the relationship between shape, orientation and window-towall ratio (WWR) with the thermal comfort and energy consumption in buildings. Summary of the analysed articles is shown in Table 1. All reviewed articles are categorised based on different criteria, including the year of study, continent, country, climate, type of building, building form and the studied parameters.

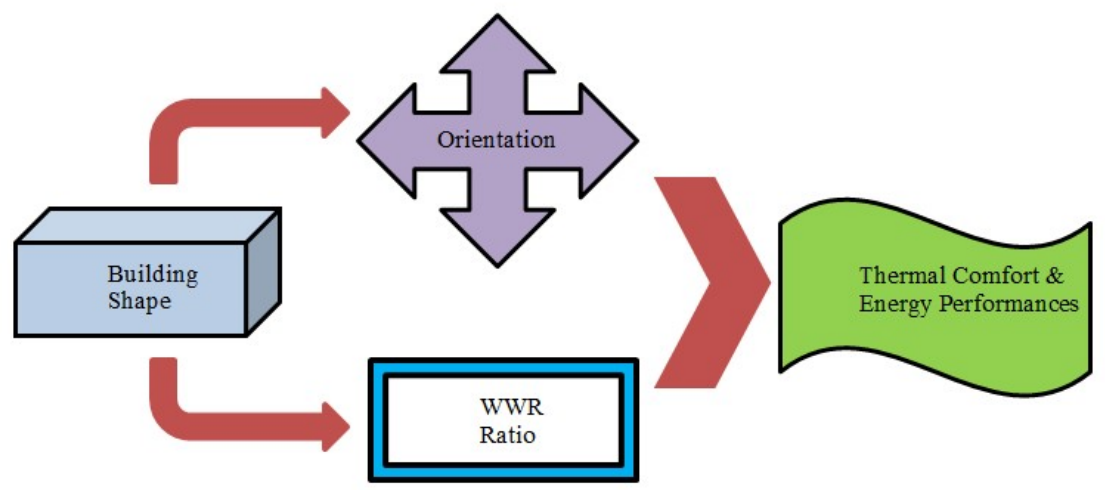

Fig. 2. Conceptual framework.

Table 1. Summary of the analysed articles.

\begin{tabular}{|c|c|c|c|c|c|c|c|c|c|c|c|c|c|c|}
\hline \multirow[b]{2}{*}{$\begin{array}{l}\text { Type of } \\
\text { building }\end{array}$} & \multirow[b]{2}{*}{ Year } & \multirow[b]{2}{*}{ 壱 } & \multirow[b]{2}{*}{ 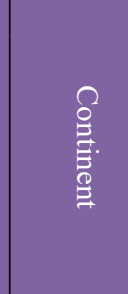 } & \multirow[b]{2}{*}{$\begin{array}{l}\text { ᄋ } \\
\text { 衾 }\end{array}$} & \multirow[b]{2}{*}{ 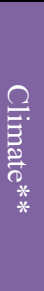 } & \multicolumn{3}{|c|}{ Form } & \multicolumn{6}{|c|}{ Parameter } \\
\hline & & & & & & $\begin{array}{l}5 \\
\vdots \\
\vdots \\
\vdots \\
0 \\
0 \\
0\end{array}$ & 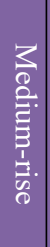 & 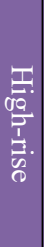 & 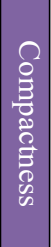 & 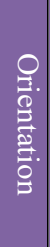 & 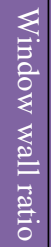 & 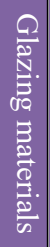 & 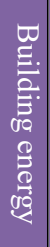 & 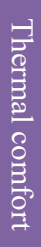 \\
\hline \multirow[t]{4}{*}{ Office } & 2017 & [6] & $\begin{array}{l}\text { Australia } \\
\text { Asia } \\
\text { Europe }\end{array}$ & $\begin{array}{l}\text { Sydney } \\
\text { Singapore } \\
\text { Amsterdam }\end{array}$ & $\begin{array}{l}\mathrm{C} \\
\mathrm{A} \\
\mathrm{C}\end{array}$ & & & $\checkmark$ & $\checkmark$ & $\checkmark$ & $\checkmark$ & $\checkmark$ & $\checkmark$ & \\
\hline & 2015 & {$[7]$} & America & US & $\mathrm{C}$ & $\checkmark$ & & & $\checkmark$ & & & & $\checkmark \mid$ & \\
\hline & 2008 & [8] & Asia & Kuwait & $\mathrm{B}$ & & & $\checkmark$ & $\checkmark$ & $\checkmark$ & $\checkmark$ & $\checkmark$ & $\checkmark$ & \\
\hline & 2016 & [9] & Asia & Malaysia & $\mathrm{A}$ & & $\checkmark$ & & $\checkmark$ & $\checkmark$ & & & $\checkmark$ & \\
\hline \multirow[t]{2}{*}{ Residential } & 2017 & {$[10]$} & Asia & China & $\mathrm{C}$ & $\checkmark$ & & & $\checkmark$ & $\checkmark$ & $\checkmark$ & & $\checkmark$ & \\
\hline & 2014 & {$[11]$} & America & US & A & $\checkmark$ & & & $\checkmark$ & & & & $\checkmark$ & \\
\hline \multirow[t]{8}{*}{ Others } & 2015 & {$[12]$} & Asia & Iran & $\mathrm{C}$ & $\checkmark$ & & & $\checkmark$ & $\checkmark$ & $\checkmark$ & & $\checkmark$ & \\
\hline & 2015 & {$[13]$} & Europe & Portugal & $\mathrm{C}$ & $\checkmark$ & & & $\checkmark$ & & $\checkmark$ & & & $\checkmark$ \\
\hline & 2012 & {$[14]$} & Asia & Korea & D & & & $\checkmark$ & $\checkmark$ & & & & $\checkmark$ & \\
\hline & 2012 & {$[15]$} & Europe & Sweden & D & $\checkmark$ & & & $\checkmark$ & & $\checkmark$ & & $\checkmark$ & $\checkmark$ \\
\hline & 2012 & {$[16]^{*}$} & Various & Various & & $\checkmark$ & & & $\checkmark$ & $\checkmark$ & & $\checkmark$ & $\checkmark$ & \\
\hline & 2011 & {$[17]$} & Europe & France & $\mathrm{C}$ & $\checkmark$ & & & $\checkmark$ & & & $\checkmark$ & $\checkmark$ & \\
\hline & 2007 & {$[18]$} & Asia & Malaysia & $\mathrm{A}$ & & & $\checkmark$ & & $\checkmark$ & & & $\checkmark$ & \\
\hline & 2001 & {$[19]$} & Europe & France & $\mathrm{C}$ & $\checkmark$ & $\checkmark$ & $\checkmark$ & $\checkmark$ & & & & $\checkmark$ & \\
\hline
\end{tabular}

Note $-*$ Review of previous works

- **The climate type is based on the climate classification by Köppen Geiger 


\section{Building Shape Factor}

Solar radiation received by the building is not only determined by the shape, but also by the total façade and roof area. Besides that, the surface that exposed to the outside also plays an important role in controlling the heat losses and gains by the building [16]. Two main factors used to define the building shape are building compactness and relative compactness. The equations for compactness (C) and relative compactness (RC) are given as Eq. 1 and Eq. 2 respectively below:

$$
\begin{gathered}
\mathrm{C}=\mathrm{V} / \mathrm{A}_{\text {ext }} \\
\mathrm{RC}=\mathrm{C}_{\text {building }} / \mathrm{C}_{\mathrm{ref}}
\end{gathered}
$$

\subsection{Building Compactness}

Compactness of a building is defined as the ratio of building surface area exposed to solar radiation $\left(\mathrm{A}_{\mathrm{ext}}\right)$ to the volume of building $(\mathrm{V})[8,12,15,16]$. Higher surface area of the building exposed to the outdoor environment will lead to less compact shape where the heat can be easily gained or lost from the building surface area. Fig. 3 shows the compactness between two buildings of the same volume.

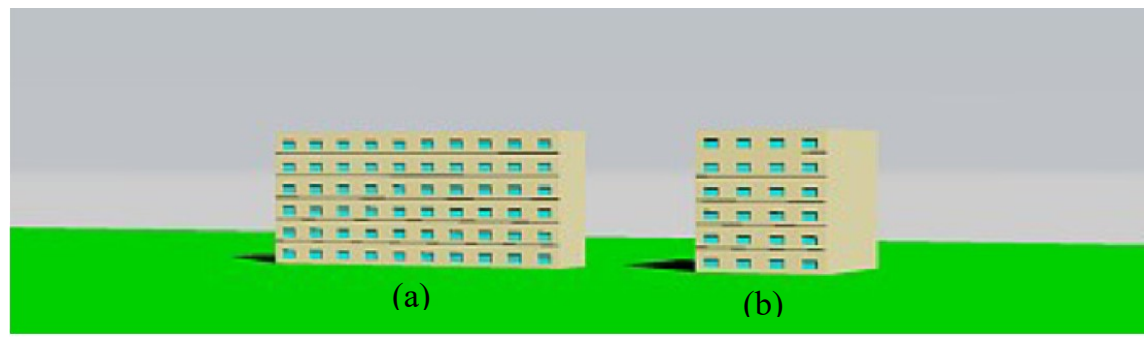

Fig. 3. Building compactness : (a) $\mathrm{C}=3.45$; (b) $\mathrm{C}=5$ [16].

\subsection{Relative Compactness}

Relative compactness is the compactness index that is based on the reference building. The reference building in this context is the most compact shape with the same volume [17]. Different shape of the building will have a different surface area exposed to the outdoor environment. Hence, the same building volume, but greater in the exposed surface area to the outdoor environment will contribute to the less compact shape.

Building compactness has an important role in heat loss or gain in buildings. However, according to Kasmee in Fallahtafti, the impact of building compactness is only applicable to the small amount of building openings where the effect of solar radiation can be neglected $[12,20]$. The impact of building compactness on thermal performance was studied in Europe by Rodrigues et al. [13], where they found that the existing building energy regulations has lead to the increase of insulation thickness and high performance windows, which has caused the reduction of heat loss through building skin, thus lesser impact on the indoor thermal conditions.

Catalina et al. [17] found that the energy consumption of buildings increases with the decrease in building compactness. This finding was supported by other studies which showed that the less compact buildings contribute to the increase of energy demand of buildings $[8,9,12,15,19]$. Lu et al. [10] conducted a research on the building energy performance of single, double, and three storey buildings which have different building 
volumes and exposed areas. The study showed that the three storey building consumes less energy as compared to the other buildings. From the calculation of compactness, the three storey building has a higher value of compactness, $C$, which means that the surface exposure is less than the total building volume.

\section{Combination of Building Shape, Orientation and Window-to Wall Ratio}

There have been few studies on the effect of building shape on energy consumption [612,14,16-19]. However, literatures that associate building shapes and thermal performance are scarce and limited. On the other hand, Danielski et al. [15] and Rodrigues et al. [13] did explore the impact of building compactness on building thermal performance.

\subsection{Building Orientation}

Another factor that contributes to the building performance is building orientation. This is one of the efforts to control heat gains by blocking and filtering solar radiation from entering the building [18]. The lower the radiation, the amount of energy needed to cool the indoor space will reduce. In order to control the amount of solar radiation entering the building, it is important to understand how it affects heat gains and losses in a building.

Raji et al. [6] conducted a research on three different climates and locations; Amsterdam (temperate), Sydney (Sub-tropical) and Singapore (tropical). The impacts of building orientations were analysed based on the climate and solar path of the locations where the studies took place. Fig. 4 shows the solar path of the three different locations and climates. The solar path depends on the latitude where the building is located.

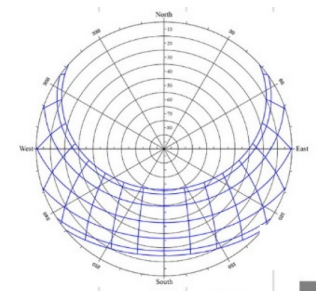

(a)

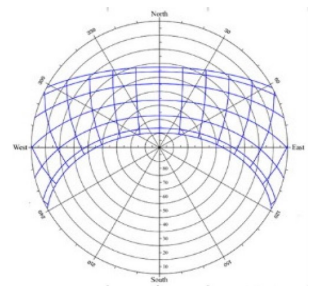

(b)

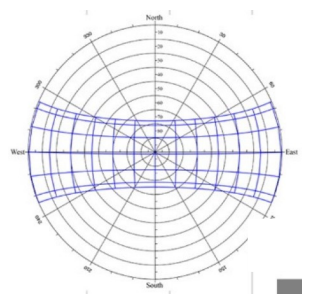

(c)

Fig. 4. Solar path in (a) Amsterdam (temperate) ; (b) Sydney (sub-tropical) ; (c) Singapore (tropical) [6].

Amsterdam that is located in the northern hemisphere has more seasonal variations. The solar path during winter and summer are slightly different, but the south-facing orientation is the most critical to solar radiation [10,21-23]. In comparison with Sydney, where it is located in the southern hemisphere, the North-facing orientation is the most extremely exposed to solar radiation. For seasonal climate, the exposure of building facades to solar radiation gives some advantages by allowing natural lighting and heat gain, which can reduce the heating and lighting energy used in the building. On the other hand, the excess of radiation during summer can be reduced by applying blind or overhangs [6].

East-West facing is the critical orientation for Singapore as it is located near the Equator, where the solar path does not change much throught out the year [6]. This similarity can be found in other studies conducted near the equator region such as Malaysia and Indonesia [24-33]. These researchers suggested that the East-West orientation for buildings near the equator region should be avoided. 
Raji et al. [6] study shows that, the largest energy consumption occurs in sub-tropical climate while the least occurs in the tropical climate. Table 2 shows the building shape and relative compactness of the building studied. Ellipse (shape 3) is found to be the most optimum shape in all climates. In contrast, the Y-shape (shape 12) is found to be the worst shape for energy efficiency in all climate conditions. As for tropical climate, the octagon (shape 2) is found to be the most efficient building shape. Other researchers found that circular shape is the most optimum shape in tropical climate $[9,18]$.

Table 2. Building shapes and its relative compactness [6].

\begin{tabular}{|c|c|c|c|c|c|c|}
\hline Shape & $\overline{1}$ & 2 & 3 & $\overline{4}$ & 5 & 6 \\
\hline $\begin{array}{l}\text { Relative } \\
\text { Compactness }\end{array}$ & $100 \%$ & $103 \%$ & $107 \%$ & $113 \%$ & $128 \%$ & $130 \%$ \\
\hline Shape & 7 & 8 & $\overline{9}$ & 10 & 11 & 12 \\
\hline $\begin{array}{l}\text { Relative } \\
\text { Compactness }\end{array}$ & $157 \%$ & $175 \%$ & $175 \%$ & $176 \%$ & $176 \%$ & $178 \%$ \\
\hline
\end{tabular}

A study on mixed-used high-rise buildings in Korea shows that the tower type buildings consume more energy than the plate type building in terms of electricity consumption by the residents [14]. Residents feedback on the survey conducted reveals that the tower-type apartment buildings receive excessive light in summer, thus contributes to a higher energy demand for cooling purpose. Another research done on thermal performance in Nordic climate showed that the impact of building shape is lesser in a warmer climate [15].

In reducing the solar radiation entering into the building, the facade orientation angle plays an important role. A study by Chia et al. [18] shows that the highest solar insolation received on high-rise buildings is from its vertical wall with $86.6 \%$ of the annual insolation. Hence, optimizing the facade orientation is a must in reducing the impact of solar radiation, especially in tropical climate.

Al-Anzi [8] stated that the building orientation effects the energy consumption of the building. However, the orientation of the building is not influenced by the building shape when the amount of glazing is smaller, where the effect of solar radiation can be neglected. However, this result was based on a different shape but similar in relative compactness, RC. Having the same RC means that the total area exposed to solar radiation is similar but depending on the orientation. This statement was supported by a research done by Fallahtafti and Mahdavinejad [12]. Further exploration requires to study the impact of RC.

Exploration on the impact of building shape with different compactness exposed to different orientation in tropical climate was conducted by Rashdi et al. [9]. From Fig. 5, it is found that the building shapes does not affect much on less compact shapes such as Lshape, T-shape, U-shape and courtyard. While for the compact and symmetric shapes such as square and circle, there is no difference in energy consumption when there are changes in directions due to the same area exposed on each cardinal. For rectangular and ellipse shapes, a higher the cooling load is required when the longest facade is oriented to the east. In order to reduce the cooling load, it is suggested to orient the building away from solar radiation to prevent excess heat gain. 


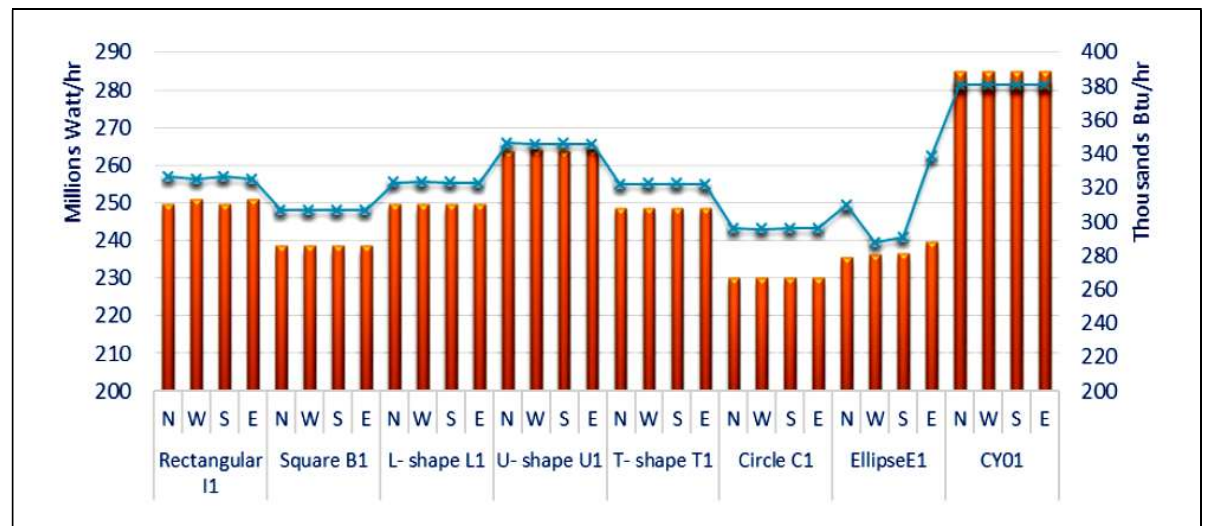

(a)

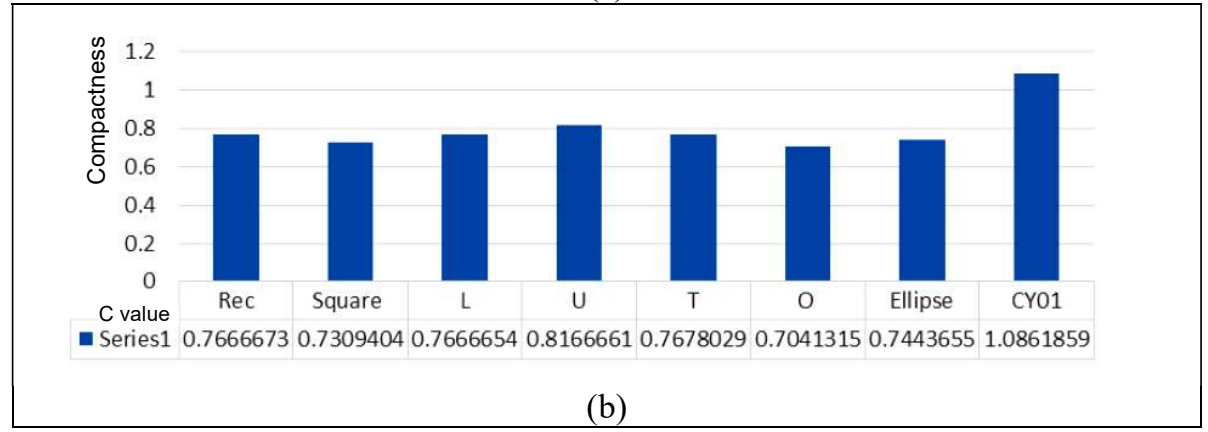

Fig. 5. (a) Cooling load of basic building shapes (b) Compactness of the building shapes [9].

A study on the impact of building shapes in hot summer and cold winter in China showed that the South orientation of the building reduces the energy consumption. This is due to the natural lighting and higher heat gain from the south facade which contributes to the lower energy demand for heating [10]. Similar results were found in a study conducted in Tehran to determine the impact of building on optimize building orientation. This study was based on 8 cubes $(2 \mathrm{~m} \times 2 \mathrm{~m} \times 2 \mathrm{~m})$ arranged in multiple ways to produce different shapes and compactness. From the outcomes, the optmised orientation of all modules are in the range of 298 to 318 degrees (South-west to South) [12].

Overall, studies showed that the optimum building orientation is influenced much by the building shapes, but depending on the solar path of the location. However, another crucial factor in determining the impact of changing orientation of the building is the ground plan area. The smaller ground area is found to be less sensitive and good in thermal performance when there is a change in building orientation. A larger ground plan area which greater than $200 \mathrm{~m}^{2}$ shows a lower adaptibility on thermal performances when the orientation varies [34]. However, the exploration on this factor is scarce and limited in the studies on building shape.

\subsection{Window-to-wall Ratio}

The impact of window-to-wall ratio (WWR) was studied by Al-Anzi et al. [8] to determine its relationship with building shapes. The building without a window opening (WWR $=0 \%$ ) and partially glazed (WWR $=50 \%$ ) having the same floor area and height but different in compactness were studied. From the results, a similar pattern was found in both cases. The building consumes more energy when the shape of the building is less compact. However, a 
slight different on energy consumption of a building having the same compactness but different in shape was found. This is due to the different perimeter exposed and the orientation in relations to solar radiation.

The relationship between optimised orientation and glazing area was studied by Fallahtafti and Mahdavinejad [12]. The combinations of 8 cubic modules consists of two Trombe wall (South and East) and two windows (West and North) with glazing percentages of $25 \%, 50 \%$ and $70 \%$ are shown in Fig. 6 . Low amount of glazing (WWR=25\%) caused the building to be inclined more to the west. This result was due to the unique design of cubic prototype, where the location of trombe wall and window opening played and important role in absorbing the solar radiation.

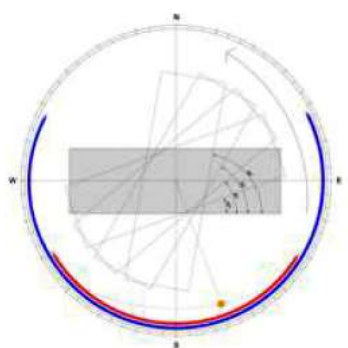

(a)

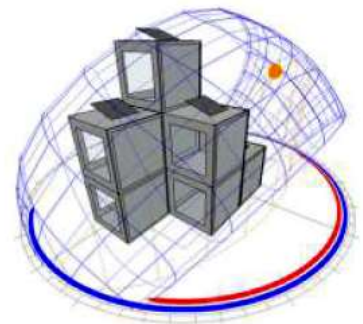

(b)

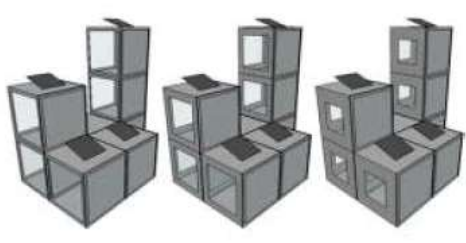

(c)

Fig. 6. (a) Orientation of the building $360^{\circ}$; (b) Position of the building in solar path (Tehran) ; (c) Different glazing percentages $(25,50$ and 70 respectively) [12].

\section{Conclusion}

In the last decade, the increase in the number of high-rise buildings and application of glass façade had shown some impacts on the performances of buildings. This review highlights some of the important key points with regard to the thermal conditions in buildings and its energy consumption. Selection and application of the appropriate building shape and its factors at the early stage of the design process will help in improving the building performance.

The authors would like to thank the Universiti Tun Hussein Onn Malaysia (UTHM) and Ministry of Higher Education Malaysia (MOHE) for financial support which made this work possible.

\section{References}

1. Department of Economic and Social Affairs, World Urbanization Prospects: The 2014 Revision, (2015.

2. M. Santamouris, Natural Ventilation in the Urban Environment: Assessment and Design,: pp. 1-19, (2015)

3. [3] A. Bastide, P. Lauret, F. Garde, H. Boyer, Energy Build., 38, 1093-1103, (2006).

4. D.G. Zenginis, K.J. Kontoleon, Environ. Sci. Pollut. Res., 1-11, (2017).

5. C. Rubio-Bellido, A. Pérez-Fargallo, J.A. Pulido-Arcas, Energy., 114, 569-585, (2016).

6. B. Raji, M.J. Tenpierik, A. van den Dobbelsteen, Sustainability, 9, 623 (2017). 
7. M. Mottahedi, A. Mohammadpour, S.S. Amiri, D. Riley, S. Asadi, Procedia Eng., 118, 622-629, (2015).

8. A. AlAnzi, D. Seo, M. Krarti, Energy Convers. Manag., 50, 822-828,(2009).

9. W.S.S.W.M. Rashdi, M.R. Embi, Procedia - Soc. Behav. Sci., 222, 782-790, (2016).

10. S. Lu, X. Tang, L. Ji, D. Tu, Sustainability, 9, 294, (2017).

11. S. Asadi, S.S. Amiri, M. Mottahedi, Energy Build., 85, 246-255, (2014).

12. R. Fallahtafti, M. Mahdavinejad, Int. J. Energy Sect. Manag., 9, 593-618, (2015).

13. E. Rodrigues, A.R. Amaral, A.R. Gaspar, Á. Gomes, Energy Convers. Manag., 101, 561-578, (2015).

14. I.Y. Choi, S.H. Cho, J.T. Kim, Energy Build., 46, 123-131, (2012).

15. I. Danielski, M. Fröling, A. Joelsson, World Renew. Energy Forum, WREF 2012, Incl. World Renew. Energy Congr. XII Color. Renew. Energy Soc. Annu. Conf., 4260-4264, (2012).

16. R. Pacheco, J. Ordóñez, G. Martínez, Renew. Sustain. Energy Rev., 16, 3559-3573, (2012).

17. T. Catalina, J. Virgone, V. Iordache, Proc. Build. Simul., 1726-1729, (2011).

18. S.L. Chia, A. Mohd Hamdan, O. Dilshn Remaz, J. Constr. Dev. Ctries., 12, 27-28, (2007).

19. P. Depecker, C. Menezo, J. Virgone, S. Lepers, Build. Environ., 36, 627-635, (2001).

20. M. Kasmaee, Climate and Architecture, (2006).

21. I. Susorova, M. Tabibzadeh, A. Rahman, H.L. Clack, M. Elnimeiri, Energy Build., 57, 6-13, (2013).

22. X. Su, X. Zhang, Energy Build., 42, 198-202, (2010).

23. S.K. Alghoul, H.G. Rijabo, M.E. Mashena, J. Build. Eng., 11, 82-86, (2017).

24. N.A. Naamandadin, A.R. Sapian, S.N.A. Mohd Noor, Key Eng. Mater., 700, 247-255, (2016).

25. A.K.K. Lau, E. Salleh, C.H. Lim, M.Y. Sulaiman, Int. J. Sustain. Built Environ., 5, 387-399, (2016).

26. R.A. Mangkuto, M. Rohmah, A.D. Asri, Appl. Energy., 164, 211-219,(2016).

27. A. Aflaki, N. Mahyuddin, M.R. Baharum, Energy Build., 126, 146-158, (2016).

28. L.P. Chung, M.H. Ahmad, D.R. Ossen, M. Hamid, M. Baharvand, J. Sustain. Dev., 4, 631-636, (2014).

29. N.A. Al-Tamimi, S.F.S. Fadzil, Procedia Eng., 21, 273-282, (2011).

30. N.A. M. Al-Tamimi, S.F. Syed Fadzil, W.M. Wan Harun, J. Sustain. Dev., 4, 142149, (2011).

31. M. Sembiring, Proc. Int. Conf. Appl. Des. Mech. Eng, 11-13, (2009).

32. S. Loekita, J. Priatman, Civ. Eng. Dimens., 17, 108-115, (2015).

33. M.M. Tahmasebi, S. Banihashemi, M.S. Hassanabadi, Procedia Eng., 21, 820-828 (2011).

34. J. Morrissey, T. Moore, R.E. Horne, Renew. Energy., 36, 568-577, (2011). 